\title{
Clinical Trial Site Communications and Tracking Management Documentation
}

National Cancer Institute

\section{Source}

National Cancer Institute. Clinical Trial Site Communications and Tracking Management

Documentation. NCI Thesaurus. Code C115781.

Records pertaining to the management of a clinical trial site. 